\title{
Pyruvate kinase (Pyk1) levels influence both the rate and direction of carbon flux in yeast under fermentative conditions
}

\author{
Amanda K. Pearce, ${ }^{1} \dagger$ Kay Crimmins,${ }^{1} \ddagger$ Evelyne Groussac, ${ }^{2}$ \\ Michael J. E. Hewlins, ${ }^{3}$ J. Richard Dickinson, ${ }^{4}$ Jean Francois, ${ }^{2}$ \\ Ian R. Booth ${ }^{1}$ and Alistair J. P. Brown ${ }^{1}$
}

Author for correspondence: Alistair J. P. Brown. Tel: +44 1224 273183. Fax: +44 1224273144. e-mail: al.brown@abdn.ac.uk

\footnotetext{
1 Molecular and Cell Biology, Institute of Medical Sciences, University of Aberdeen, Foresterhill, Aberdeen AB25 2ZD, UK

2 Centre de Bioingenierie Gilbert Durand, UMR-CNRS 5504 UR-INRA 792 Département de Génie Biochimique et Alimentaire, Institut National des Sciences Appliquées, 31077 Toulouse Cedex 04, France

3 Department of Chemistry, Cardiff University, PO Box 912, Cardiff CF10 3TB, UK

4 Cardiff School of Biosciences, Cardiff University, PO Box 915, Cardiff CF10 3TL, UK
}

\begin{abstract}
Yeast phosphofructo-1-kinase (Pf1k) and pyruvate kinase (Pyk1) are allosterically regulated enzymes that catalyse essentially irreversible reactions in glycolysis. Both the synthesis and activity of these enzymes are tightly regulated. To separate experimentally the control of Pf1k and Pyk1 synthesis from their allosteric regulation, a congenic set of PFK1, PFK2 and PYK1 mutants was constructed in which these wild-type coding regions were driven by alternative promoters. Mutants carrying PGK1 promoter fusions displayed normal rates of growth, glucose consumption and ethanol production, indicating that the relatively tight regulation of Pyk1 and Pf1k synthesis is not essential for glycolytic control under fermentative growth conditions. Mutants carrying fusions to an enhancer-less version of the PGK1 promoter (PGK1 $\left.{ }_{\triangle 767}\right)$ expressed Pyk1 and Pf1k at about 2·5-fold lower levels than normal. Physiological and metabolic analysis of the PFK1 PFK2 double mutant indicated that decreased Pf1k had no significant effect on growth, apparently due to compensatory increases in its positive effector, fructose 2,6-bisphosphate. In contrast, growth rate and glycolytic flux were reduced in the PGK1 ${ }_{\triangle 767}-P Y K 1$ mutant, which had decreased Pyk1 levels. Unexpectedly, the reduced Pyk1 levels caused the flow of carbon to the TCA cycle to increase, even under fermentative growth conditions. Therefore, Pyk1 exerts a significant level of control over both the rate and direction of carbon flux in yeast.
\end{abstract}

Keywords: Glycolysis, metabolic flux, pyruvate kinase, phosphofructokinase, yeast physiology

\section{INTRODUCTION}

The glycolytic pathway is arguably the best characterized metabolic pathway in Saccharomyces cerevisiae (reviewed by Johnston \& Carlson, 1992; Dickinson, 1999). The glycolytic enzymes can comprise up to $30-50 \%$ of total soluble protein during growth on a fermentable carbon source (Hess et al., 1969; Fraenkel,

\footnotetext{
†Present address: MRC Radiation and Genome Stability Unit, Harwell, Didcot, Oxfordshire OX11 ORD, UK.

‡Present address: Quest International, Menstrie, Clackmannanshire SK11 7ES, UK.

Abbreviations: MCA, metabolic control analysis; Pf1k, 6-phosphofructo1-kinase; Pyk1, pyruvate kinase.
}

1982; Gancedo \& Serrano, 1989). Most yeast glycolytic enzymes have been purified and their biochemical properties characterized, and many have had their crystal structures determined. All of the yeast glycolytic genes have been isolated and sequenced, and their regulation has been the subject of intense investigation. However, our understanding of the factors that control metabolic flux through this pathway in vivo under 'normal' physiological conditions remains relatively limited.

Once hexoses have been transported into the yeast cell and phosphorylated, they have several alternative metabolic routes. Hexose phosphates may be utilized for trehalose, glycogen or cell-wall biosynthesis, or catabolized via the glycolytic or pentose phosphate pathways. 
The first glycolytic-specific reaction involves the generation of fructose 1,6-bisphosphate. Most glycolytic enzymes catalyse reversible reactions that are also utilized for the opposing pathway, gluconeogenesis. Therefore, early studies on glycolytic regulation focused on those enzymes that catalyse essentially irreversible reactions in this pathway and hence are specific to glycolysis such as 6-phosphofructo-1-kinase (Pf1k) and pyruvate kinase (Pyk1). Both of these enzymes are subject to significant allosteric regulation (Hunsley \& Suelter, 1969; Bañuelos et al., 1977; Avigad, 1981; Bartrons et al., 1982; Fraenkel, 1982; Arvantidis \& Heinisch, 1994; Heinisch et al., 1996). Hence, Pf1k and Pyk1 were viewed as catalysing rate-limiting steps in glycolysis; this view still dominates conventional thinking. In addition, the genes encoding Pf1k and Pyk1 appear to be regulated more tightly than other glycolytic genes. Pyk 1 is a homotetramer, the monomer being encoded by PYK1 (Burke et al., 1983). Pf1k is a heterooctamer, the $\alpha$ and $\beta$ subunits being encoded by PFK1 and PFK2 (Heinisch, 1986). The PYK1, PFK1 and PFK2 genes appear to be regulated at both the transcriptional and translational levels (Moore et al., 1990a, b, c, 1991). From a genetic viewpoint, it seemed attractive to suggest that these regulatory phenomena might contribute to the control of glycolysis.

Metabolic control analysis (MCA) suggests that all enzymes in a biochemical pathway contribute to some extent to metabolic flux through that pathway (Kacser \& Burns, 1973, 1979; Fell, 1997). Under some specific circumstances a particular enzyme might exert a high degree of control over the flux through a pathway and hence be rate limiting with respect to this flux. However, this is unlikely to be the case for enzymes that are subject to allosteric regulation, because according to MCA theory, a consequence of allosteric regulation is the potential transfer of some flux control to other steps in the pathway (Kacser \& Burns, 1973, 1979; Fell, 1984, 1997). This view is reinforced by the general observation that the overexpression of regulatory enzymes subject to feedback inhibition did not significantly increase flux through the corresponding pathways (Fell, 1997), and the specific observation that the overexpression of individual glycolytic enzymes in yeast did not increase fermentation rates significantly (Schaaff et al., 1989; Davies \& Brindle, 1992). Hence, from an MCA perspective, the Pf1k and Pyk1 enzyme levels, controlled in part through PYK1, PFK1 and PFK2 gene regulation, are unlikely to exert a high level of control over glycolytic flux.

To examine these contrasting views of glycolytic regulation in yeast, we have studied the consequences of (a) disturbing the transcriptional and post-transcriptional regulation of the PYK1, PFK1 and PFK2 genes and (b) altering Pyk1 and Pf1k levels upon yeast physiology. The data suggest that gene regulation plays a minor role in the control of glycolytic flux under fermentative growth conditions, and that Pyk1 levels influence both the rate and direction of carbon flux in yeast.

\section{METHODS}

Growth conditions. Strains were grown in YPD $(2 \%, w / v$, glucose; $2 \%, \mathrm{w} / \mathrm{v}$, bactopeptone; $1 \%, \mathrm{w} / \mathrm{v}$, yeast extract), YPL (3\%, v/v, lactate; $2 \%, \mathrm{w} / \mathrm{v}$, bactopeptone; $1 \%, \mathrm{w} / \mathrm{v}$, yeast extract), GYNB (2\%, w/v, glucose; $0.65 \%, \mathrm{w} / \mathrm{v}$, yeast nitrogen base without amino acids) or SC (Strathern et al., 1994).

Strain construction. All of the glycolytic mutants constructed in this study were made in S. cerevisiae W303-1B (Thomas \& Rothstein, 1989). To generate these mutants (Table 1), promoterless or promoter-containing 3 '-truncated versions of the PYK1, PFK1 and PFK2 genes were integrated into the corresponding chromosomal locus (Fig. 1). To achieve this, nine plasmids were constructed in which the three glycolytic 3 -truncated ORFs lacked a promoter or were fused to the PGK1 or $P G K 1_{\triangle 767}$ promoters (Ogden et al., 1986). All of the necessary PCR amplifications were performed using $P f u$ polymerase (Stratagene). The nine plasmids were transformed

Table 1. Strains used in this study

\begin{tabular}{|c|c|}
\hline Strain & Genotype \\
\hline \multicolumn{2}{|c|}{ Parental strain } \\
\hline W303-1B & MAT $\alpha$ ade 1 ade 2 leu 2 his 3 ura 3 trp 1 \\
\hline \multicolumn{2}{|c|}{ PGK1 promoter fusions } \\
\hline YKC1 & $\begin{array}{l}\text { MAT } \alpha \text { ade } 1 \text { ade } 2 \text { leu } 2 \text { his } 3 \text { ura3 trp1 } \\
\text { PGK1p-PYK1-URA3 }\end{array}$ \\
\hline YKC2 & $\begin{array}{l}\text { MAT } \alpha \text { ade1 ade } 2 \text { leu } 2 \text { his } 3 \text { ura3 trp1 } \\
\text { PGK1p-PFK1-HIS3 }\end{array}$ \\
\hline YKC3 & $\begin{array}{l}\text { MAT } \alpha \text { ade1 ade } 2 \text { leu } 2 \text { his } 3 \text { ura3 trp1 } \\
\text { PGK1p-PFK2-TRP1 }\end{array}$ \\
\hline YKC4 & $\begin{array}{l}\text { MAT } \alpha \text { ade } 1 \text { ade } 2 \text { leu } 2 \text { his } 3 \text { ura } 3 \text { trp } 1 \\
\text { PGK1p-PFK1-HIS3 PGK1p-PFK2-TRP1 }\end{array}$ \\
\hline YKC5 & $\begin{array}{l}\text { MAT } \alpha \text { ade1 ade2 leu2 his3 ura3 trp1 } \\
\text { PGK1p-PFK1-HIS3 PGK1p-PFK2-TRP1 } \\
\text { PGK1p-PYK1-URA3 }\end{array}$ \\
\hline \multicolumn{2}{|c|}{$P G K 1_{\triangle 767}$ promoter fusions } \\
\hline YKC11 & $\begin{array}{l}\text { MAT } \alpha \text { ade1 ade } 2 \text { leu2 his3 ura3 trp1 } \\
P G K 1_{\Delta 767}-P Y K 1-U R A 3\end{array}$ \\
\hline YKC12 & $\begin{array}{l}\text { MAT } \alpha \text { ade1 ade } 2 \text { leu } 2 \text { his } 3 \text { ura3 trp1 } \\
P G K 1_{\triangle 767}-P F K 1-H I S 3\end{array}$ \\
\hline YKC13 & $\begin{array}{l}\text { MAT } \alpha \text { ade1 ade2 leu2 his3 ura3 trp1 } \\
\text { PGK1 } 1_{\Delta 767}-\text { PFK2-TRP1 }\end{array}$ \\
\hline YKC14 & $\begin{array}{l}\text { MAT } \alpha \text { ade } 1 \text { ade } 2 \text { leu } 2 \text { bis } 3 \text { ura3 trp1 } \\
P G K 1_{\Delta 767}-P F K 1-H I S 3 \text { PGK1 } 1_{\Delta 767}-P F K 2-T R P 1\end{array}$ \\
\hline YKC15 & $\begin{array}{l}\text { MAT } \alpha \text { ade1 ade2 leu2 bis3 ura3 trp1 } \\
P G K 1_{\Delta 767}-P F K 1-H I S 3 P G K 1_{\Delta 767}-P F K 2-T R P 1 \\
P G K 1_{\Delta 767}-P Y K 1-U R A 3\end{array}$ \\
\hline \multicolumn{2}{|c|}{ Promoterless fusions } \\
\hline YKC21 & $\begin{array}{l}\text { MAT } \alpha \text { ade1 ade2 leu2 bis } 3 \text { ura } 3 \text { trp1 } \\
\Delta p y k 1-U R A 3\end{array}$ \\
\hline YKC22 & MAT $\alpha$ ade 1 ade 2 leu 2 his 3 ura 3 trp1 $\Delta p f k 1-H I S 3$ \\
\hline YKC23 & $\begin{array}{l}\text { MAT } \alpha \text { ade1 ade } 2 \text { leu2 bis } 3 \text { ura } 3 \text { trp1 } \\
\text { Apfk2-TRP1 }\end{array}$ \\
\hline YKC24 & $\begin{array}{l}\text { MAT } \alpha \text { ade } 1 \text { ade } 2 \text { leu2 his } 3 \text { ura3 trp1 } \Delta p f k 1-H I S 3 \\
\Delta p f k 2-T R P 1\end{array}$ \\
\hline YKC25 & $\begin{array}{l}\text { MAT } \alpha \text { ade1 ade2 leu2 his3 ura3 trp1 } \Delta p f k 1-H I S 3 \\
\Delta p f k 2-T R P 1 \Delta p y k 1-U R A 3\end{array}$ \\
\hline
\end{tabular}


(a)

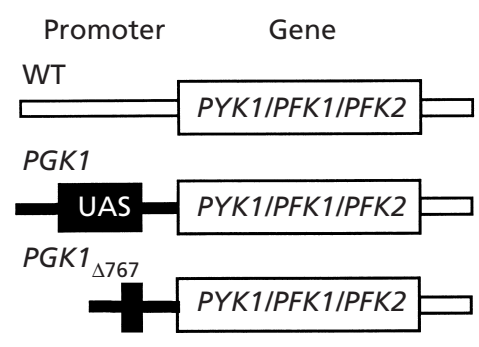

(b)

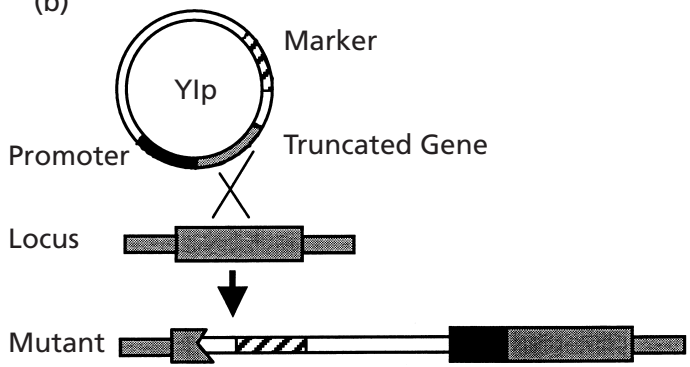

(c)

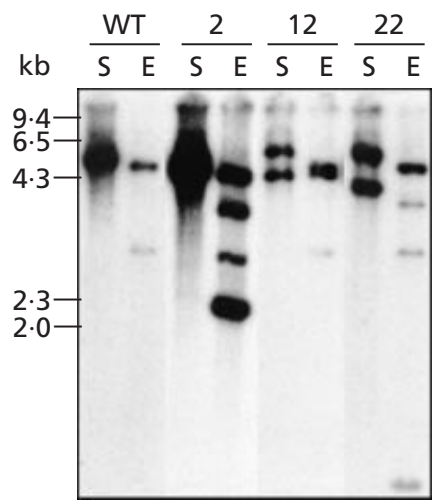

Fig. 1. Construction of the YKC mutants. (a) Cartoon illustrating structure of the YKC mutations. The $P Y K 1, P F K 1$ or $P F K 2$ coding region is indicated by a white box; wild-type promoter, thick black line; PGK1 promoter, black box with UAS marked; $P G K_{\triangle 767}$, promoter with UAS deleted. Promoterless mutants were also created (not shown). The resultant strains are listed in Table 1. (b) Cartoon illustrating the construction of the YKC mutants. Ylp-based plasmids containing the appropriate promoter fused to a $3^{\prime}$-truncated version of the appropriate coding region were integrated at the corresponding chromosomal locus to generate a truncated gene with its wild-type promoter and a wild-type coding region (grey) with its new promoter (black). (c) Southern blot confirming correct single-copy integration of pPGK-PFK1, pPGK $_{4767}$-PFK1 and pPFK1 to generate YKC2, YKC12 and YKC22, respectively: WT, W303-1B; 2, YKC2; 12, YKC12; 22, YKC22. Genomic DNA was digested with Sall (S) or EcoRI (E) and probed with the BamHI-Sacll PFK1 insert from pPFK1. Positions of size markers $(\mathrm{kb})$ are shown. Compared to W303-1B, each mutant has additional bands of the expected lengths. Southern analyses for the other mutants is presented in Crimmins (1995).

Table 2. PCR primers used in this study

Restriction sites are underlined.

\begin{tabular}{|c|c|c|c|c|}
\hline Primer & Sequence $\left(\mathbf{5}^{\prime}-\mathbf{3}^{\prime}\right)$ & $\begin{array}{l}\text { Restriction } \\
\text { site }\end{array}$ & Coordinates & $\begin{array}{l}\text { ORF } \\
\text { length }\end{array}$ \\
\hline 5'PYK1 & CAAGTAAAGGATCCTAACAATGTCTAGATTAG & BamHI & -5 & - \\
\hline 3’PYK1 & 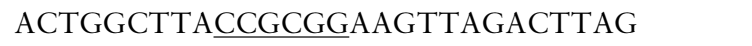 & SacII & +882 & 1500 \\
\hline 5'PFK1 & TCTGAAACAAAATCGGATCCAAGATGCAATCTC & BamHI & -3 & - \\
\hline 3'PFK1 & CAATTCATCAACCGCGGATGGCCATTCG & SacII & +987 & 2961 \\
\hline 5'PFK2 & CAAGAACTAAGGATCCACAATGACTGTTAC & BamHI & -3 & - \\
\hline 3’PFK2 & CCGACAGTACCGCGGATATTCAAATG & SacII & +1033 & 2877 \\
\hline 5'PGK1 & TTTAGCTTCCAAGCTTCAACTCAAGACGCACAG & HindIII & - & - \\
\hline 3'PGK1 & AAGATAAAGACATAGATCTTATATTTGTTG & $B g l \mathrm{II}$ & - & - \\
\hline
\end{tabular}

into S. cerevisiae (Gietz \& Woods, 1998) and single-copy integration at the appropriate glycolytic locus confirmed by Southern analysis.

The first $882 \mathrm{bp}$ of the PYK1 ORF, $987 \mathrm{bp}$ of the PFK1 ORF and $1033 \mathrm{bp}$ of the PFK2 ORF were PCR amplified using the primers described in Table 2, cloned as BamHI-SacII fragments into pRS306, pRS303 and pRS304, respectively (Sikorski \& Hieter, 1989) and resequenced. This generated the promoterless constructs pPYK1, pPFK1 and pPFK2. The PGK1 promoter was isolated as a $1.5 \mathrm{~kb} E c o \mathrm{RI}-B g l \mathrm{II}$ fragment from pMA91 (Mellor et al., 1985). This fragment was cloned into pPYK1, pPFK1 and pPFK2 to generate the PGK1 fusions in the plasmids, pPGK-PYK1, pPGK-PFK1 and pPGK-PFK2, respectively. The $P G K 1_{\Delta 767}$ promoter was PCR amplified from pMA767 (Ogden et al., 1986) using the primers 5'PGK1 and 3'PGK1 (Table 2) and cloned as a $0.78 \mathrm{~kb}$ HindIII-BglII fragment into pLH1 (Amersham). This HindIII-BglII fragment was then cloned into pPYK1 to generate the plasmid pPGK $_{\Delta 767}-\mathrm{PYK} 1$. To avoid multiple HindIII restriction sites in pPFK1 and pPFK2, the $P G K 1_{\triangle 767}-P F K$ fusions were created in two stages. First, the HindIII-BglII PGK ${ }_{\triangle 767}$ fragment and the BamHI-SacII PFK1 fragment were cloned between the HindIII and SacII sites in pRS306 using a three-way ligation. Then the resultant $P G K 1_{\triangle 67}-P F K 1$ fusion was cloned as a XhoI-SacII fragment into pRS303 to make pPGK ${ }_{\Delta 767}-\mathrm{PFK} 1$. The same approach was used to generate pPGK ${ }_{\Delta 767}-\mathrm{PFK} 2$ from $\mathrm{pRS} 304$.

The three PYK1 plasmids, pPYK1, pPGK-PYK1 and pPGK $_{\Delta 767}-\mathrm{PYK} 1$, were linearized within the 3 '-truncated ORF using BglII and transformed into W303-1B, selecting for the URA 3 marker. The three PFK1 plasmids were linearized with $\mathrm{XbaI}$ and W303-1B transformants selected using the HIS3 marker. The three PFK2 plasmids were linearized with StuI 
and W303-1B transformants selected using TRP1. Double and triple mutants were generated by transforming single and double mutants with the appropriate plasmids.

Southern, Northern and Western blotting. S. cerevisiae DNA was isolated according to the protocol of Hoffman \& Winston (1987) and subjected to Southern blotting (Church \& Gilbert, 1984; Wicksteed et al., 1994). Standard methods were used for yeast RNA preparation and Northern analysis (Brown, 1994; Planta et al., 1999). Signals were quantified by phosphorimaging, and mRNA levels were measured relative to the ACT1 mRNA which acted as an internal control for variations in RNA loading on gels (Moore et al., 1991; Planta et al., 1999). Hybridization probes were as follows: PFK1, the $3 \cdot 2 \mathrm{~kb}$ EcoRI fragment from pPFK1 (Heinisch, 1986); PFK2, the $3 \mathrm{~kb}$ EcoRI fragment from pPFK2 (Heinisch, 1986); PYK1, the $0.89 \mathrm{~kb}$ BamHI-SacII fragment from pPYK1; ACT1, the $1.5 \mathrm{~kb}$ HindIII-EcoRI fragment from pSPACT9 (Moore et al., 1991). Random-primed labelling of DNA fragments was carried out using $\left[\alpha^{32} \mathrm{P}\right] \mathrm{dCTP}$ with the Pharmacia Ready-ToGo DNA Labelling Kit, which is based on the method of Feinberg \& Vogelstein (1983).

For extraction of total soluble protein from yeast, $50 \mathrm{ml}$ cells was grown to mid-exponential phase in YPD or SC at $30^{\circ} \mathrm{C}$. Cells were harvested at $3000 \mathrm{~g}$ for $5 \mathrm{~min}$, washed twice in $1 \mathrm{M}$ sorbitol and resuspended in 200-300 $\mu$ l extraction buffer [20 mM HEPES, pH 7.5, 0.2 mM EDTA, 1.5 $\mathrm{mM} \mathrm{MgCl}_{2}, 25 \%$ $(\mathrm{w} / \mathrm{v})$ glycerol, $0.5 \mathrm{mM}$ DTT, Complete protease inhibitor cocktail tablets (Boehringer Mannheim)]. Samples were vortexed with glass beads six times for $1 \mathrm{~min}$ with $1 \mathrm{~min}$ intervals on ice between vortexing and centrifuged at $14000 \mathrm{~g}$ for $15 \mathrm{~min}$ at $4{ }^{\circ} \mathrm{C}$. Supernatants were stored at $-80^{\circ} \mathrm{C}$ in extraction buffer containing $2 \mathrm{mM}$ fructose 2,6-bisphosphate (Reibstein et al., 1986). Protein extracts were electrophoresed on SDS-polyacrylamide gels and Western analysis performed using published protocols (Laemmli, 1970; Towbin et al., 1979). Nitrocellulose membranes were probed using a polyclonal antiserum against yeast Pfk (Heinisch et al., 1996). The second antibody was anti-rabbit IgG-alkaline phosphatase conjugate (Boehringer Mannheim).

Enzyme assays. Pyruvate kinase assays were carried out as described previously (Hunsley \& Suelter, 1969; Yun et al., 1976). Phosphofructo-1-kinase assays were carried out in duplicate using previously published procedures (Racker, 1947; Reibstein et al., 1986). Protein determinations were performed using the Bradford assay (Bradford, 1976).

Metabolite assays. Glucose, ethanol and glycerol assays were carried out in triplicate using Boehringer Mannheim kits. Methylglyoxal assays were performed in triplicate using the procedure of Ferguson et al. (1995). Measurements of intracellular metabolites (glucose 6-phosphate, fructose 6phosphate, fructose 1,6-bisphosphate and ATP) after a glucose pulse to yeast cells were performed by coupling with NADH production or consumption as described by Bergmeyer (1986). Fructose 2,6-bisphosphate was measured according to Van Schaftingen et al. (1982). For the glucose-pulse experiment, yeast strains were grown to an $\mathrm{OD}_{600}$ of $2 \cdot 0$ in GYNB, harvested by centrifugation, washed once with water and resuspended at an $\mathrm{OD}_{600}$ of 5.0 in $25 \mathrm{mM}$ potassium phosphate buffer, pH 6.0. After $30 \mathrm{~min}$ pre-incubation, glucose was added to $1 \%$, and $5 \mathrm{ml}$ samples were collected at various times and quenched in cold methanol. Metabolites were extracted in buffered ethanol as described in Gonzalez et al. (1997). Errors for metabolite assays were between 5 and $10 \%$.

NMR. Briefly, cells were grown to an $\mathrm{OD}_{600}$ of 0.6 and labelled with $20 \mathrm{mg}\left[1{ }^{-13} \mathrm{C}\right]$ glucose $\mathrm{ml}^{-1}$ (99 atom \%; Sigma) in SC medium for $45 \mathrm{~min}$ at $30^{\circ} \mathrm{C}$. The cells were harvested by centrifugation and perchloric acid extracts were prepared for ${ }^{13} \mathrm{C}$ NMR as described previously (Dickinson \& Hewlins, 1988, 1991). The spectra were recorded as described by Dickinson et al. (1997) using a Bruker AMX360 spectrometer operating at $90.5 \mathrm{MHz}$ using $32 \mathrm{~K}$ data points over $22 \mathrm{kHz}$ with Waltz-16 ${ }^{1} \mathrm{H}$ decoupling and by the DEPT method to determine the number of protons attached to each carbon atom. Signals were identified by comparison with spectra of standard compounds recorded under identical conditions. Standard Bruker software (UXNMR) was used throughout. Chemical shifts were reported relative to external tetramethyl silane in $\mathrm{C}^{2} \mathrm{HCl}_{3}$. Addition of sodium trimethylsilylpropanesulphonate gave a methyl signal at -2.6 p.p.m. under the conditions used here.

\section{RESULTS}

\section{Construction of PYK1, PFK1 and PFK2 mutants}

Previously, one of our groups had reported that the expression of the PYK1 and PFK2 genes is more tightly regulated than other glycolytic genes. PYK1 and PFK2 mRNA levels are induced to greater extents by glucose, and these mRNAs also appear to be co-regulated at the translational level (Moore et al., 1990a, b, c, 1991). Therefore, we were interested in establishing the importance of this regulation to the control of glycolysis. Hence in this study, our first aim was to examine the effects of disrupting the normal regulation of the PYK1, $P F K 1$ and PFK2 genes. The transcriptional and translational regulation of PYK1 is dependent upon its promoter and 5' leader sequence (Moore et al., 1990a, b, c, 1991). Therefore these sequences were replaced with those of the PGK1 gene since this gene is not subject to the same degree of regulation as PYK1 (Moore et al., 1991). Analogous mutations were also made for PFK1 and PFK2 (Fig. 1).

A second aim was to establish the effects of downregulating Pyk1 and Pf1k levels. To address this aim, a

Table 3. PYK1 expression levels during growth on glucose

Numbers in parentheses are percentage of wild-type.

\begin{tabular}{|llcc|}
\hline Strain & $\begin{array}{c}\text { Relevant } \\
\text { genotype }\end{array}$ & $\begin{array}{c}\text { Relative } \\
\text { PYK1 } \\
\text { mRNA } \\
\text { level* }\end{array}$ & $\begin{array}{c}\text { Pyruvate kinase } \\
\text { specific activity }\end{array}$ \\
& & $3 \cdot 0(100)$ & $3 \cdot 2 \pm 0 \cdot 09(100)$ \\
W303-1B & Wild-type & $4 \cdot 5(150)$ & $3 \cdot 6 \pm 0 \cdot 04(125)$ \\
YKC1 & $P G K 1 p-P Y K 1$ & $1 \cdot 3(43)$ & $0 \cdot 77 \pm 0 \cdot 25(24)$ \\
YKC11 & $P G K 1_{\Delta 767}-P Y K 1$ & NM $(-)$ & NM $(-)$ \\
YKC21 & $\Delta p y k 1$ & & \\
\hline
\end{tabular}

*PYK1 mRNA levels were measured relative to the ACT1 mRNA in arbitrary units.

†Units are $\mu \mathrm{mol} \min ^{-1}$ (mg protein $)^{-1}$.

$\ddagger$ The pyk1 null mutant was not viable on glucose. NM, Not measurable. 

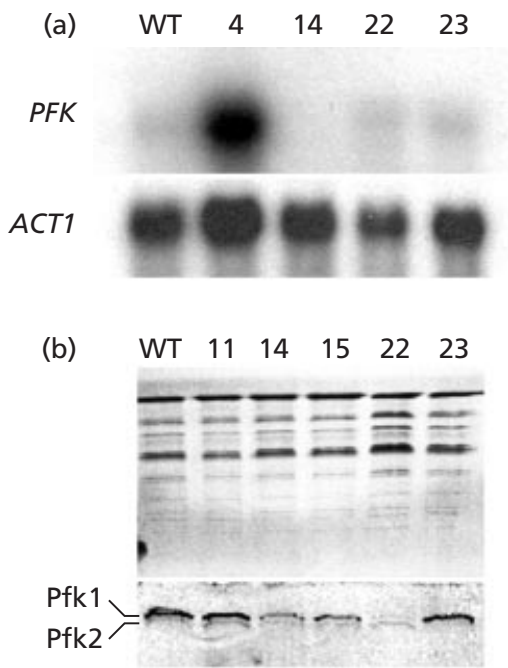

Fig. 2. $P f 1 k$ expression in $Y K C$ mutants. (a) Northern analysis of PFK1/2 mRNA levels compared to the ACT1 mRNA. Membranes were probed with the ECORI PFK2 fragment from PPFK2 (which cross-hybridizes with the PFK1 mRNA), stripped and reprobed for ACT1. Relative PFK1 mRNA levels are presented in Table 4. Similar data were obtained with the PFK1 probe (not shown). (b) Western analysis of Pf1k subunits using polyclonal antiserum against yeast $\mathrm{Pf} 1 \mathrm{k}$. The upper panel shows the Coomassie stained gel, and the lower panel shows the Western blot. Pfk1 and Pfk2 subunits are marked. WT, W303-1B; 4, YKC4 (PGK1p-PFK1 PGK1p-PFK2); 11, YKC11 (PGK1 $\left.{ }_{\triangle 767}-P Y K 1\right)$; 14, YKC14 (PGK1 $\left.{ }_{\triangle 767}-P F K 1 \quad P G K 1_{\Delta 767}-P F K 2\right) ; 15$, YKC15 $\left(P G K 1_{\triangle 767}-P F K 1 \quad P G K 1_{\triangle 767}-P F K 2 \quad P G K 1_{\triangle 767}-P Y K 1\right) ; 22$, YKC22 $(\Delta p f k 1) ; 23$, YKC23 ( $\Delta p f k 2)$.

second set of mutants was made in which the PYK1, PFK1 and PFK2 loci were placed under the control of the $P G K 1_{\triangle 767}$ promoter and $5^{\prime}$ leader sequences. This promoter lacks the PGK1 upstream activator sequence required for efficient and regulated expression $(-389$ to -473 with respect to the ATG; Ogden et al., 1986; Piper et al., 1988).
The strategy for the construction of these mutants involved the integration of 3 -truncated ORFs fused to the new promoter region (Fig. 1). Single-copy integration at the correct glycolytic locus was confirmed for each mutant by Southern blotting (e.g. Fig. 1c). This strategy generated a tandemly repeated locus where the native glycolytic promoter drives a 3'-truncated version of the gene and the new promoter drives the synthesis of the wild-type glycolytic enzyme.

\section{Expression of PYK1, PFK1 and PFK2 in the mutants}

For this strategy to be successful, the PYK1, PFK1 and PFK2 genes had to be inactivated by the 3 -truncation event (Fig. 1b). To test this presumption, promoterless mutants were also made. As expected, the promoterless $p y k 1$ and $p f k 1$ pfk2 mutants (YKC21 and YKC24) were unable to grow on glucose. Furthermore, the PYK1 mRNA was not detectable by Northern analysis in the pyk1 mutant, and the PFK1 and PFK2 mRNAs were not detectable in the $p f k 1 p f k 2$ double mutant, following growth of these strains on YPL (not shown). Therefore, $3^{\prime}$ truncation did inactivate each of these loci, and the synthesis of Pyk1 and Pf1k was dependent on the PGK1 or $P G K 1_{\triangle 767}$ promoters in the mutants.

PYK1, PFK1 and PFK2 expression levels were examined in the mutants during growth on glucose. Relative to their congenic parent (W303-1B), PYK1 mRNA levels were slightly elevated in the mutant carrying the PGK1-PYK1 fusion (YKC1; 150\%) and were reduced in the strain with the $P G K 1_{\triangle 767}-P Y K 1$ fusion (YKC11; $43 \%$; Table 3 ). Analogous observations were made for the corresponding double PFK mutants: PFK1 and PFK2 mRNA levels were elevated in YKC4 $(240 \%)$ and reduced in YKC14 (40\%; Table 4, Fig. 2b). Pyk1 and Pf1k assays confirmed that the reductions in mRNA levels had led to roughly equivalent changes in the levels of these enzymes (Tables 3 and 4). In addition, decreased levels of each Pf1k subunit (Pfk1p and Pfk2p) were

Table 4. PFK1 and PFK2 expression levels during growth on glucose

Numbers in parentheses are percentage of wild-type.

\begin{tabular}{|llcc|}
\hline Strain & \multicolumn{1}{|c|}{ Relevant genotype } & $\begin{array}{c}\text { Relative } \\
\text { PFK1/2 } \\
\text { mRNA } \\
\text { level* }\end{array}$ & $\begin{array}{c}\text { Phosphofructokinase } \\
\text { specific } \\
\text { activity }\end{array}$ \\
\hline W303-1B & Wild-type & $0 \cdot 1(100)$ & $1 \cdot 3 \pm 0 \cdot 1(100)$ \\
YKC4 & $P G K 1 p-P F K 1 P G K 1 p-P F K 2$ & $0 \cdot 22(220)$ & ND \\
YKC14 & $P G K 1_{\Delta}-P F K 1 P G K 1_{\Delta}-P F K 2$ & $0 \cdot 04(40)$ & $0 \cdot 8 \pm 0 \cdot 01(62)$ \\
YKC24 $\neq$ & $\Delta p f k 1 \Delta p f k 2$ & NM $(-)$ & NM $(-)$ \\
\hline
\end{tabular}

* The PFK1 probe detected both the PFK1 and PFK2 mRNAs, which were measured relative to the ACT1 mRNA in arbitrary units.

†Units are $10^{2} \mu \mathrm{mol} \mathrm{min}^{-1}$ (mg protein $)^{-1}$. ND, Not done.

$\ddagger$ Not viable on glucose. NM, Not measurable. 

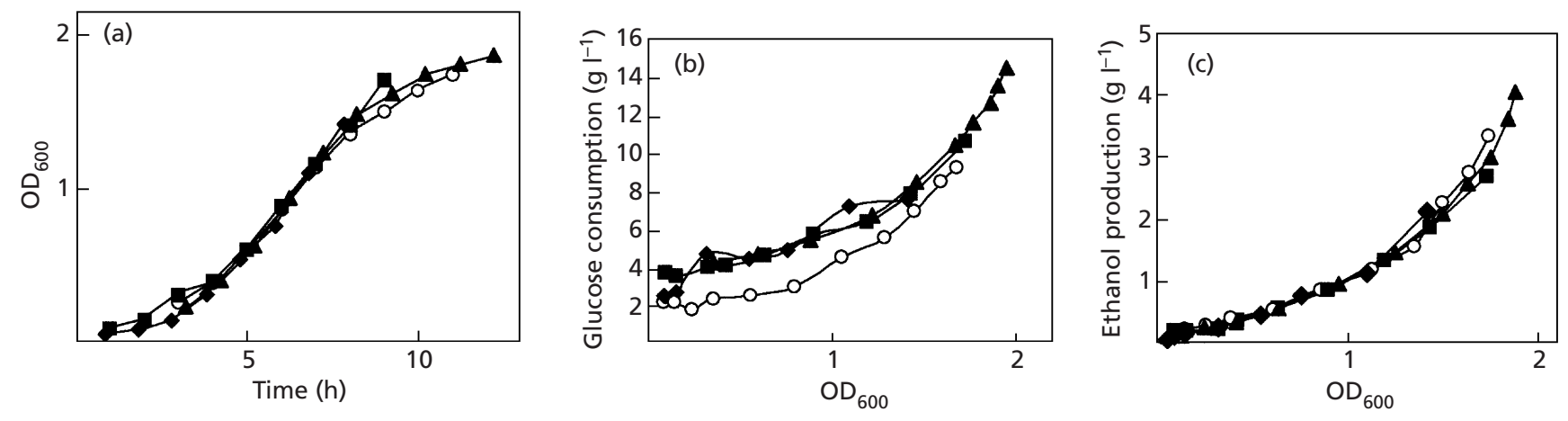

Fig. 3. Effect of the $P G K 1$ promoter fusions upon growth in SC containing $2 \%$ glucose. Growth was monitored using $\mathrm{OD}_{600}(\mathrm{a})$, and samples were taken to measure glucose consumption (b) and ethanol production (c) per unit biomass (relative to $\left.\mathrm{OD}_{600}\right)$. W303-1B (wild-type), O; YKC1 (PGK1p-PYK1), $\bullet$ YKC4 (PGK1p-PFK1 PGK1p-PFK2), ם; YKC5 (PGK1p-PFK1 PGK1p-PFK2 PGK1p-PYK1), $\boldsymbol{\Delta}$
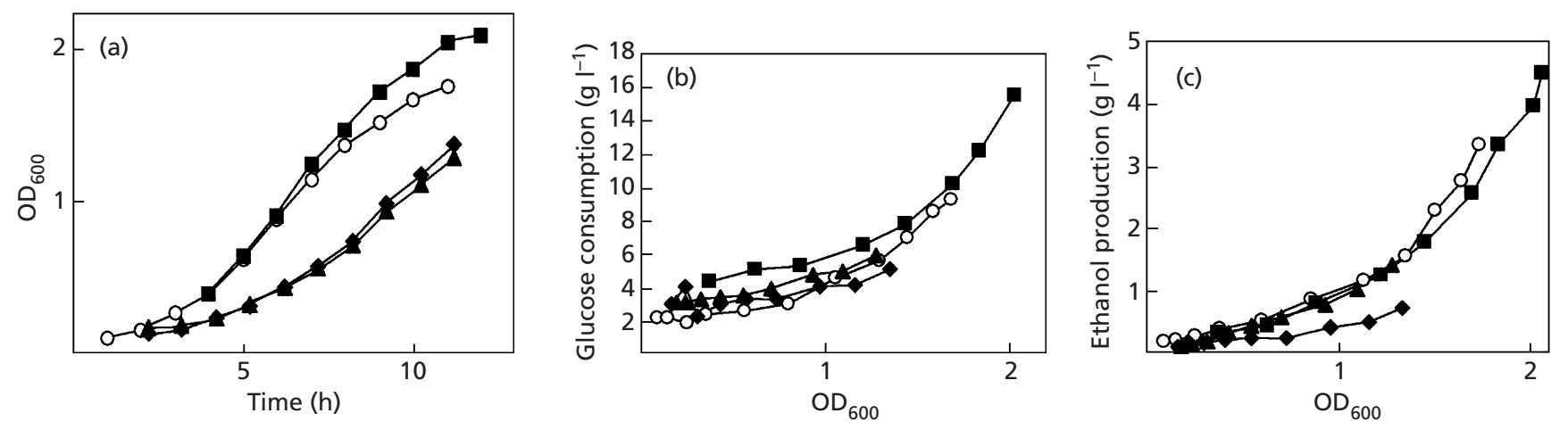

Fig. 4. Effect of the $P G K 1_{\triangle 767}$ promoter fusions upon growth in SC containing $2 \%$ glucose. Growth was monitored using $\mathrm{OD}_{600}(\mathrm{a})$, and samples were taken to measure glucose consumption (b) and ethanol production (c) per unit biomass

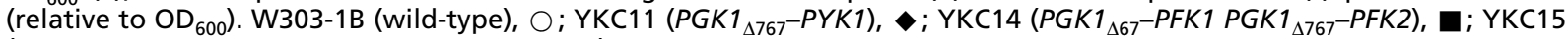
$\left(P G K 1_{\triangle 767}-P F K 1^{P G K} 1_{\triangle 767}-P F K 2\right.$ PGK1 $\left.{ }_{\Delta 767}-P Y K 1\right), \Delta$.
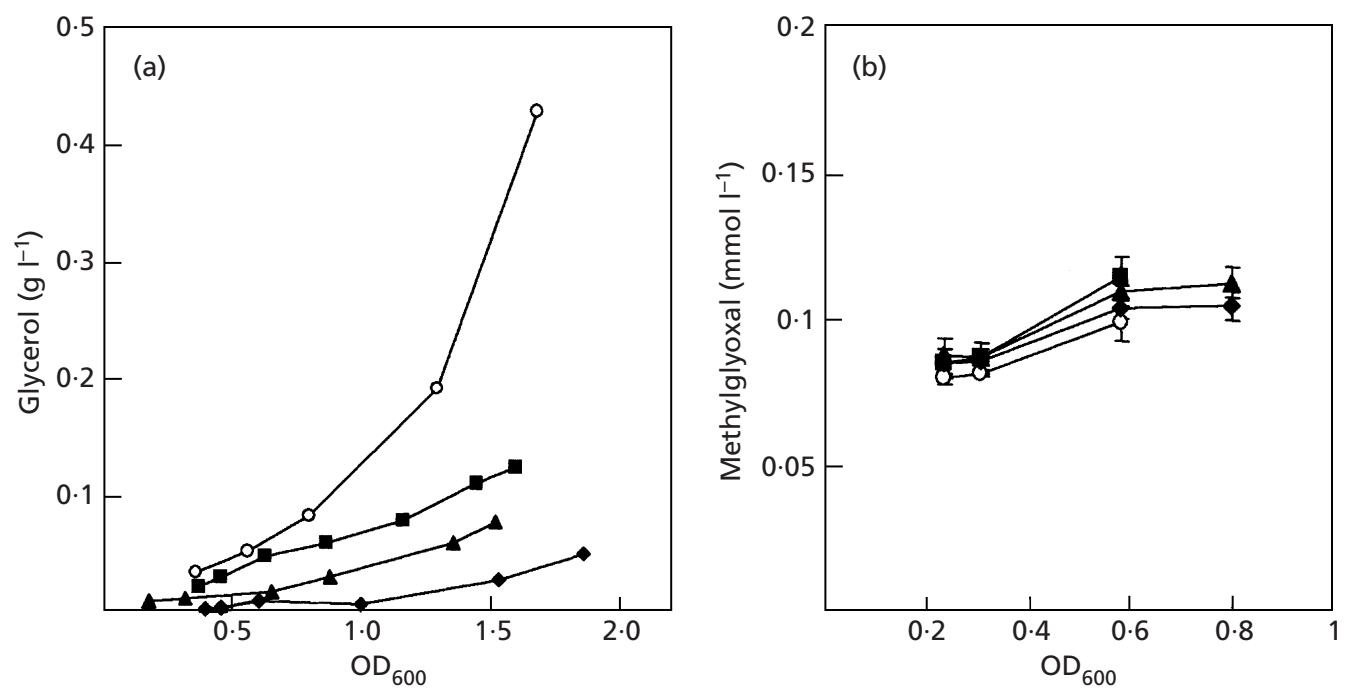

Fig. 5. Glycerol and methylglyoxal assimilation by $P G K 1_{\triangle 767}$ mutants during growth on SC containing $2 \%$ glucose. W303-

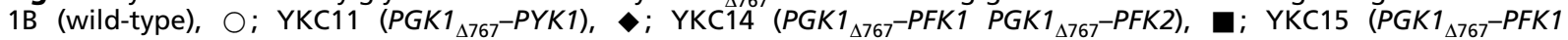
$P G K 1_{\triangle 767}-P F K 2$ PGK $\left.1_{\Delta 767}-P Y K 1\right), \boldsymbol{\Delta}$. 

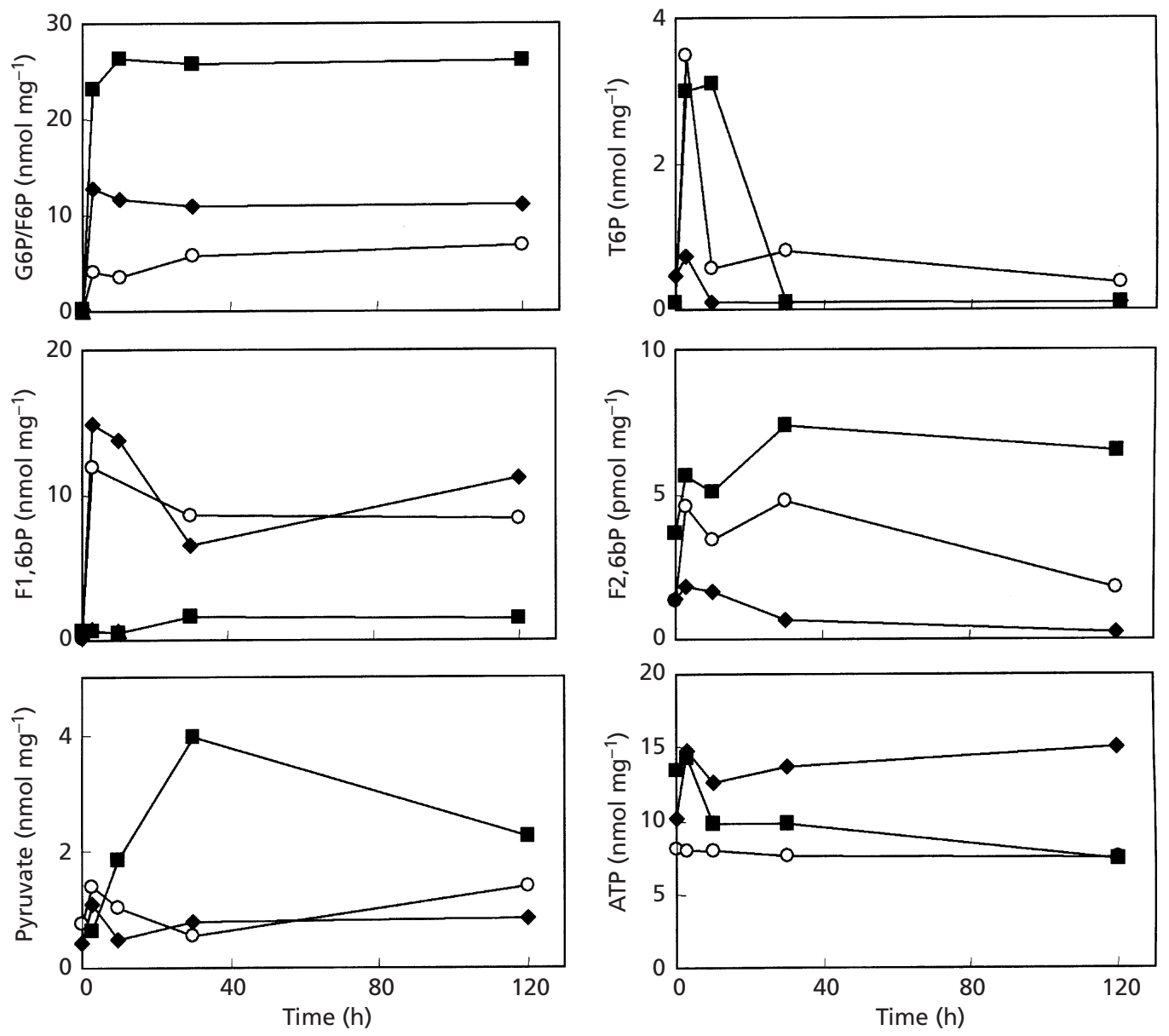

Fig. 6. Metabolite levels in $P G K 1{ }_{767}$ mutants. Strains were grown in $S D$ to an $O D_{600}$ of $0 \cdot 2$, harvested and resuspended in buffer. Glucose was then added $(1 \%)$ and cells harvested to measure metabolite levels at various times thereafter. G6P/F6P, glucose 6-phosphate plus fructose 6-phosphate; F1,6BP, fructose 1,6-bisphosphate; F2,6BP, fructose 2,6bisphosphate; T6P, trehalose 6-phosphate. W303-1B (wild-type), O; YKC11 (PGK1 $\left.{ }_{\triangle 767}-P Y K 1\right), \diamond$ YKC14 $\left(P G K 1_{\triangle 767}-P F K 1\right.$ $\left.P G K 1_{\triangle 767}-P F K 2\right)$,

confirmed in YKC14 by Western blotting (Fig. 2b). The decreases in PYK1, PFK1 and PFK2 expression levels observed for the chromosomally integrated $P G K 1_{\triangle 767}$ fusions (about 2.5-fold) were not as great as for those observed previously for a multicopy $P G K 1_{\Delta 767}-P G K 1$ gene (Ogden et al., 1986; Piper et al., 1988). Nevertheless, mutants containing the $P G K 1_{\Delta 767}$ fusions did display decreased Pyk1 and Pf1k levels, and those carrying the PGK1 promoter fusions had slightly elevated PYK1 and PFK expression levels.

\section{Physiological effects of elevated PYK1, PFK1 or PFK2 expression}

The strains carrying the PGK1 fusions were compared with their congenic parent during growth on glucose (Fig. 3). None of these strains displayed significant differences in doubling time, glucose consumption or ethanol production per unit biomass. Furthermore, they all progressed through diauxie at similar rates and displayed similar growth patterns on lactate (not shown). Therefore, the relatively acute transcriptional and translational controls that normally operate on the PYK1 and PFK1/2 genes (Moore et al., 1990a, b, c, 1991) are not essential for proper growth under these experimental conditions.

\section{Physiological effects of reduced PYK1, PFK1 or PFK2 expression}

The mutants carrying the $P G K 1_{\triangle 767}$ fusions were compared with W303-1B during growth on glucose (Fig. 4). Decreasing PFK1 and PFK2 expression levels had no significant effect on growth rate, glucose consumption or ethanol production, either in the single or double mutants (YKC12, YKC13 and YKC14). However, reducing the level of Pyk1p led to a decrease in the specific growth rate from $0.419 \pm 0.021$ (for W303-1B) to $0 \cdot 287 \pm 0 \cdot 011 \mathrm{~h}^{-1}$ (for YKC11). This mutant consumed a similar amount of glucose per unit biomass to W303-1B (Fig. 4c), but during mid-exponential growth phase, the rate of glucose consumption by YKC11 was about $65 \%$ 

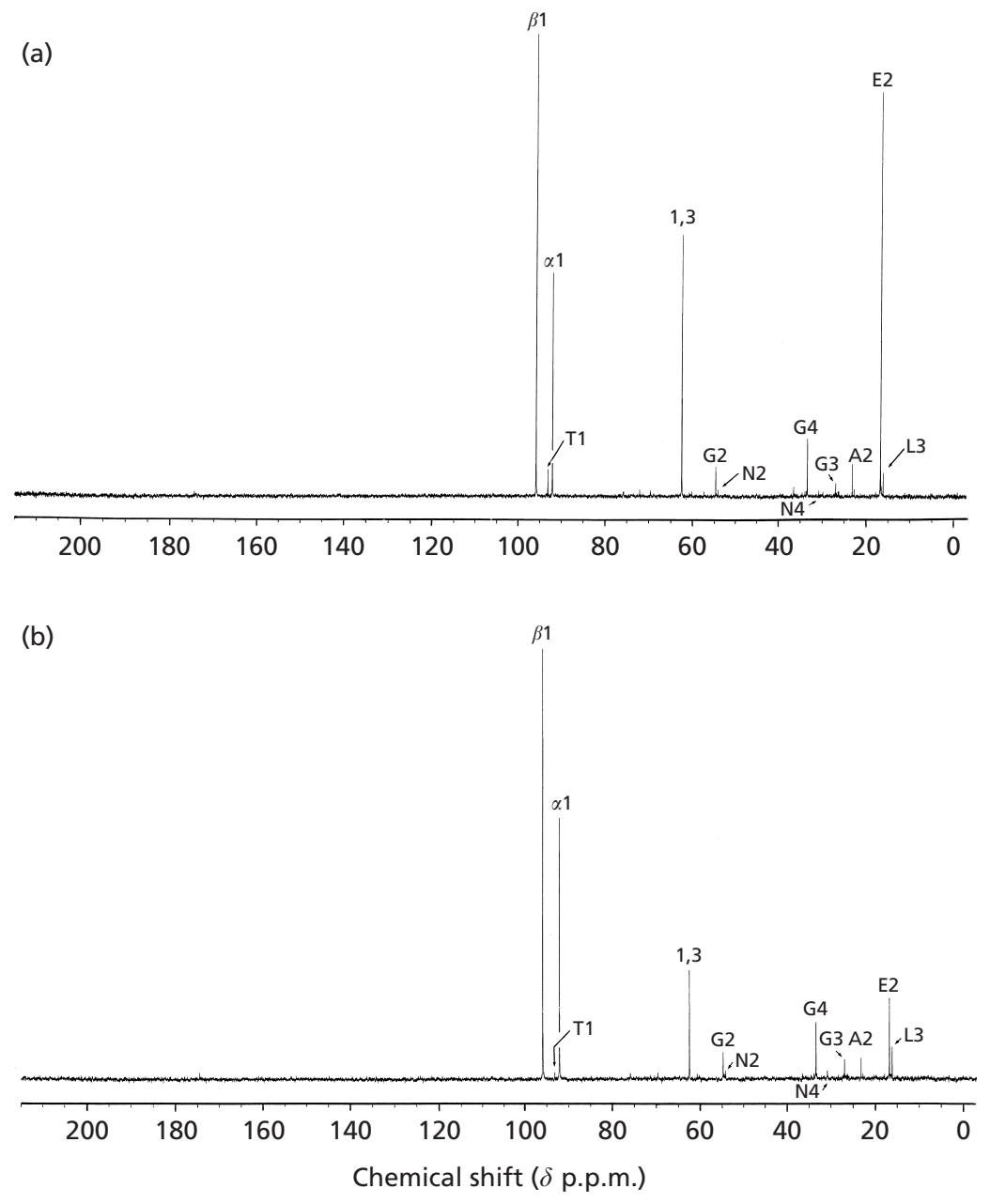

Fig. 7. ${ }^{13} \mathrm{C}$ NMR spectra of perchloric acid extracts from (a) W303-1B (wild-type) and (b) YKC11 (PGK1 $\left.{ }_{\triangle 767}-P Y K 1\right)$. Cells were incubated in the presence of $\left[1-{ }^{13} \mathrm{C}\right]$ glucose for $45 \mathrm{~min}$. The resonances marked are: $\beta 1, C-1$ of $\beta$-D-glucose; $\alpha 1, C-1$ of $\alpha$-Dglucose; 1,3, C-1,3 of glycerol; G2-G4, C2-C4 respectively of glutamate; N2, C-2 of glutamine; A2, C-2 of acetate; E2, C-2 of ethanol; L3, C-3 of alanine.

that of W303-1B. Therefore, the PGK1 $1_{\Delta 767}-P Y K 1$ mutation caused a decrease in glycolytic flux.

Compared to W303-1B, YKC11 consumed normal amounts of glucose per unit biomass, but produced about one-third of the ethanol per unit biomass (Fig. $4 b, c)$. Therefore, in this strain carbon flux was being redirected from biomass and ethanol production. It was possible that reduced flux through Pyk1p might have led to increased accumulation of glycerol or methylglyoxal (generated by dephosphorylation of dihydroxyacetone phosphate). Therefore, we examined the accumulation of glycerol and methylglyoxal in the medium of W303$1 \mathrm{~B}$ and YKC11 cultures (Fig. 5). No difference in methylglyoxal accumulation was observed, and YKC11 produced significantly lower amounts of glycerol than its parent. Therefore, the excess carbon utilized by YKC11 was not excreted as glycerol or methylglyoxal.

A reduced specific growth rate $\left(0 \cdot 25 \pm 0 \cdot 02 \mathrm{~h}^{-1}\right)$ was also observed for the triple mutant that carries reduced Pyk1p and Pf1k levels (YKC15; Fig. 4a). YKC15 also accumulated glycerol more slowly than W303-1B (Fig. 5a). However, this mutant displayed normal rates of glucose consumption, and ethanol and methylglyoxal production (Figs $4 b, c$ and $5 b$ ).

\section{Metabolite levels in PGK1 $1_{\Delta 767}$ mutants}

YKC11 metabolism was examined further by measuring the concentrations of intracellular metabolites following a pulse of glucose (Fig. 6). Glucose 6-phosphate, fructose 6-phosphate and ATP levels were increased in YKC11 compared to W303-1B, and fructose 2,6-bisphosphate and trehalose 6-phosphate levels were decreased. Fructose 1,6-bisphosphate and pyruvate levels were not affected significantly. Hence the reduction in Pyk1 levels had altered the levels of some glycolytic intermediates, effectors and ATP. However, the observed reduction in trehalose 6-phosphate levels, the maintenance of normal pyruvate levels and the increase in ATP were not consistent with a simple model involving a metabolic bottleneck at Pyk1.

The changes in metabolite levels in YKC14 $\left(P G K 1_{\Delta 767}-\right.$ PFK1 PGK1 $\left.1_{\triangle 767}-P F K 2\right)$ were consistent with the reduction in Pf1k. As expected (Teusink et al., 1998), glucose 6-phosphate, fructose 6-phosphate and initially trehalose 6-phosphate levels were increased, and fructose 1,6-bisphosphate was reduced compared to the wild-type strain (W303-1B; Fig. 6). Interestingly, the levels of fructose 2,6-bisphosphate, an allosteric activator of Pf1k, were also elevated. This was consistent 
with previous reports which have shown that compensatory changes in fructose 2,6-bisphosphate levels accompany alterations in Pf1k levels (Davies \& Brindle, 1992).

\section{${ }^{13} \mathrm{C}$ NMR analysis of glucose utilization}

Glucose consumption per unit biomass was normal in YKC11, but ethanol and glycerol production was significantly decreased (Figs 4 and 5 ). Therefore, ${ }^{13} \mathrm{C}$ NMR was used to examine the metabolic fate of the carbon utilized by YKC11. YKC11 and W3030-1B cells were labelled with $\left[1{ }^{13} \mathrm{C}\right]$ glucose, and cell extracts subjected to NMR (Fig. 7). In addition to the C-1 peaks for $\alpha$-D-glucose $(\alpha 1)$ and $\beta$-D-glucose $(\beta 1)$, three prominent signals were observed for W303-1B. Peaks E2 and 1,3 correspond to the expected glycolytic labelling of the C-2 of ethanol and C-1,3 of glycerol. Peak T1 corresponds to C-1, $1^{\prime}$ of trehalose, labelled through flux from glucose 6-phosphate. Most other peaks are indicative of glutamine and glutamate labelling via flux through the TCA cycle.

The ${ }^{13} \mathrm{C}$ NMR spectra for YKC11 and W303-1B showed significant differences (Fig. 7). Firstly, peaks E2 and 1,3 were significantly reduced for YKC11, consistent with the decreased production of ethanol and glycerol by this mutant (Figs 4c and 5a). Acetate (A2) and trehalose (T1) were both also reduced. Most significantly, peak G3 is significantly increased, relative to peaks G2 and G4 (Fig. 7). These correspond to C-3, C- 2 and C- 4 of glutamate, respectively. Entry of $\left[2-{ }^{13} \mathrm{C}\right]$ acetyl $\mathrm{CoA}$ into the TCA cycle leads to the labelling of glutamate in the C-4 position. The C-2 position also becomes labelled in the subsequent cycle, and the C-3 position is labelled in the following cycle. Therefore, the elevated level of 3labelled glutamate in YKC11 indicates that increased TCA cycling has taken place in this strain.

Increased TCA cycling might indicate that, even during growth under fermentative conditions, YKC11 is more dependent upon mitochondrial metabolism than its wild-type parent. Also, Arvantidis \& Heinisch (1994) have shown previously that a $p f k 2$ deletion mutant is respiration dependent. Therefore, we compared the effects of ethidium bromide (an inhibitor of mitochondrial function) upon YKC11 and W303-1B. The zone of growth inhibition caused by ethidium bromide was significantly greater for YKC11 $(45 \pm 7 \mathrm{~mm})$ than for W303-1B $(12 \pm 1.5 \mathrm{~mm})$, YKC14 $(11 \pm 1.5 \mathrm{~mm})$ or YKC15 $(13 \pm 2 \mathrm{~mm})$. Furthermore, unlike these other strains, YKC11 did not yield any petite colonies as a result of ethidium bromide treatment. These observations suggest that mitochondrial metabolism is required for growth of YKC11 on glucose.

\section{DISCUSSION}

In this study we have examined firstly the significance of PYK1, PFK1 and PFK2 gene regulation, and secondly the effects of reducing levels of Pyk1 and Pf1k upon fermentative metabolism in yeast. To achieve this we generated a congenic set of mutants in which the PYK1, PFK 1 and PFK 2 coding regions were placed under the control of PGK1 or $P G K 1_{\triangle 767}$ promoters (Fig. 1). Wildtype Pyk1, Pfk1 and Pfk2 proteins, which are subject to their normal allosteric controls, are synthesized in these strains. Therefore, we have separated the genetic regulation of Pyk1, Pfk1 and Pfk2 synthesis from the biochemical regulation of their activities. Physiological analyses of these strains have revealed their status following growth and adaptation to the mutations they harbour, rather than the direct metabolic effects of the mutations. Also, we cannot exclude the possibility that other glycolytic enzymes are affected by the mutations. Nevertheless, significant conclusions regarding the role of Pf1k and Pyk1 in glycoytic regulation can be drawn from our data.

Placing PYK1, PFK1 and/or PFK2 under the control of the PGK1 promoter did not have any significant effect upon growth rate on glucose or lactate, or glucose or ethanol consumption (Fig. 3). Therefore, the relatively acute genetic regulation of these loci (Moore et al., $1990 \mathrm{a}, \mathrm{b}, \mathrm{c}, 1991$ ) is not essential for growth under fermentative or gluconeogenic conditions. Tight transcriptional and translational control of, for example, PYK1 might increase the competitiveness of yeast under some conditions. Alternatively, controls at the genetic and biochemical levels may be partially redundant with respect to glycolytic regulation.

Pf1k and Pyk1 levels were elevated in YKC1 and YKC4 (Tables 3 and 4), but no significant increase in glycolytic flux was observed (Fig. 3). These data are consistent with those of Schaaf et al. (1989) who reported that glycolytic flux remains unaffected by overexpression of hexokinase, Pf1k, phosphoglycerate kinase, phosphoglycerate mutase, Pyk1, pyruvate decarboxylase or alcohol dehydrogenase. Davies \& Brindle (1992) have also shown that Pf1k overexpression does not affect glycolytic flux significantly. All of these studies have examined engineered yeast cells following a lengthy period of adaptation. Nevertheless, the data all suggest that none of these enzymes exert a high degree of control over glycolytic flux under fermentative conditions. Most of this control is thought to lie at the level of glucose import (Ye et al., 1999).

Pf1k appears to exert a relatively small amount of control over glycolytic flux under the conditions tested (Figs 3 and 4; Schaaf et al., 1989; Davies \& Brindle, 1992), and yet this enzyme is subject to tight allosteric regulation (Bañuelos et al., 1997; Avigad, 1981; Bartrons et al., 1982; Fraenkel, 1982; Arvantidis \& Heinisch, 1994; Heinisch et al., 1996). How can this be rationalized? In fact, the principles of MCA (Kacser \& Burns, 1973, 1979; Fell, 1984, 1997) predict that enzymes that display tight allosteric regulation may exert a low degree of flux control with respect to the pathway as a whole. In the case of yeast Pf1k, compensatory changes in fructose 2,6-bisphosphate may act to buffer the system under metabolic duress to maintain essential glycolytic 
flux (Davies \& Brindle, 1992). A relatively modest reduction in the level of Pf1k was achieved in this study ( $\sim 40 \%$ decrease). The elasticity of this system, achieved by compensatory modulation of fructose 2,6bisphosphate levels, might have limits. In other words, larger changes in Pf1k level might have more significant effects upon glycolytic flux.

Decreasing Pyk1 levels had unexpected effects upon the physiology of YKC11. Rates of growth and glucose consumption were reduced significantly (approx. 65\% of wild-type), indicating that glycolytic flux was reduced in this strain. Hence, Pyk1 exerts some degree of control over glycolytic flux under fermentative growth conditions. Although glucose consumption per unit biomass was normal in YKC11 (Fig. 4), ethanol and glycerol production were reduced (Figs 4 and 5), and TCA cycling was increased (Fig. 7). It seems counterintuitive to suggest that a decrease in Pyk1 caused increased TCA cycling. Nevertheless, the data clearly indicate that both the rate and direction of carbon flux was affected in this strain (YKC11).

It is not clear how a decrease in Pyk1 caused this apparent switch from fermentative to respiratory metabolism. The switch from fermentative to respiratory metabolism in yeast has been correlated with decreased growth rate (Postma et al., 1989) or glucose concentration (Meijer et al., 1998). Neither can account for the phenotypic differences observed for YKC11, YKC15 and W303-1B. YKC11 and YKC15 grew more slowly than W303-1B under conditions of glucose excess, yet only YKC11 displayed decreased ethanol production and increased mitochondrial dependence. Whatever the mechanism involved, our data suggest that Pyk1 exerts a significant level of control over both the rate and direction of carbon flux in yeast during growth on glucose.

\section{ACKNOWLEDGEMENTS}

We thank Susan Budge for excellent technical assistance. We also thank Jurgen Heinisch for the Pf1k antisera and Sue Kingsman for the $P G K 1$ and $P G K 1_{\triangle 767}$ promoters. A.K.P. and K. C. were supported by studentships from the Biotechnology and Biological Sciences Research Council.

\section{REFERENCES}

Arvantidis, A. \& Heinisch, J. J. (1994). Studies on the function of yeast phosphofructokinase subunits by in vitro mutagenesis. J Biol Chem 269, 8911-8918.

Avigad, G. (1981). Stimulation of yeast phosphofructokinase activity by fructose 2,6-bisphosphate. Biochem Biophys Res Commun 102, 985-991.

Bañuelos, M., Gancedo, C. \& Gancedo, J. M. (1977). Activation of phosphate by yeast phosphofructokinase. J Biol Chem 252, 6394-6398.

Bartrons, R., Van Schaftingen, E., Vissers, S. \& Hers, H.-G. (1982). The stimulation of yeast phosphofructokinase by fructose-2,6bisphosphate. FEBS Lett 143, 137-140.

Bergmeyer, H. U. (1986). Methods in Enzymatic Analysis, 3rd edn. Weinheim: Verlag Chemie.
Bradford, M. M. (1976). A rapid and sensitive method for the quantitation of microgram quantities of protein utilising the principle of protein-dye binding. Anal Biochem 72, 248-254.

Brown, A. J. P. (1994). Measurement of mRNA stability. In Molecular Genetics of Yeast: a Practical Approach, pp. 147-159. Edited by J. R. Johnston. Oxford: Oxford University Press.

Burke, R. L., Tekamp-Olson, P. \& Najarian, R. (1983). The isolation, characterisation and sequence of the pyruvate kinase gene of Saccharomyces cerevisiae. J Biol Chem 258, 2193-2201.

Church, G. M. \& Gilbert, W. (1984). Genomic sequencing. Proc Natl Acad Sci U S A 81, 1991-1995.

Crimmins, C. (1995). The significance of genetic regulation in the control of glycolysis in Saccharomyces cerevisiae. PhD thesis, University of Aberdeen.

Davies, S. E. C. \& Brindle, K. M. (1992). Effects of overexpression of phosphofructokinase on glycolysis in the yeast Saccharomyces cerevisiae. Biochemistry 31, 4729-4735.

Dickinson, J. R. (1999). Carbon metabolism. In The Metabolism and Molecular Physiology of Saccharomyces cerevisiae, pp. 23-55. Edited by J. R. Dickinson \& M. Schweizer. London: Taylor \& Francis.

Dickinson, J. R. \& Hewlins, M. J. E. (1988). A study of the role of the hexose monophosphate pathway with respect to fatty acid biosynthesis in sporulation of Saccharomyces cerevisiae. J Gen Microbiol 134, 333-337.

Dickinson, J. R. \& Hewlins, M. J. E. (1991). ${ }^{13} \mathrm{C}$ NMR analysis of a developmental pathway mutation in Saccharomyces cerevisiae reveals a cell derepressed for succinate dehydrogenase. J Gen Microbiol 137, 1033-1037.

Dickinson, J. R., Lanterman, M. M., Danner, D. J., Pearson, B. M., Sanz, P., Harrison, S. J. \& Hewlins, M. J. E. (1997). A ${ }^{13} \mathrm{C}$ nuclear magnetic resonance investigation of the metabolism of leucine to isoamyl alcohol in Saccharomyces cerevisiae. J Biol Chem 272, 26871-26878.

Feinberg, A. P. \& Vogelstein, B. (1983). A technique for radiolabelling DNA restriction endonuclease fragments to high specific activity. Anal Biochem 132, 6-13.

Fell, D. A. (1984). Phosphofructokinase and glycolytic flux. Trends Biochem Sci 9, 515-516.

Fell, D. A. (1997). Understanding the Control of Metabolism. London: Portland Press.

Ferguson, G. P., McLaggan, D. \& Booth, I. R. (1995). Potassium channel activation by glutathione-S-conjugates in Escherichia coli: protection against methylglyoxal is mediated by cytoplasmic acidification. Mol Microbiol 17, 1025-1033.

Fraenkel, D. G. (1982). Carbohydrate metabolism. In The Molecular Biology of the Yeast Saccharomyces: Metabolism and Biosynthesis, pp. 1-37. Edited by J. N. Strathern, E. W. Jones \& J. R. Broach. Cold Spring Harbor, NY: Cold Spring Harbor Laboratory.

Gancedo, C. \& Serrano, R. (1989). Energy yielding metabolism. In The Yeasts, vol. 3: Metabolism and Physiology of Yeasts, 2nd edn, pp. 205-259. Edited by A. H. Rose \& J. S. Harrison. London: Academic Press.

Gietz, R. D. \& Woods, R. A. (1998). Transformation of yeast by the lithium acetate/single-stranded carrier DNA/PEG method. In Yeast Gene Analysis: Methods in Microbiology, vol. 26, pp. 53-66. Edited by A. J. P. Brown \& M. F. Tuite. London: Academic Press.

Gonzalez, B., François, J. \& Renaud, M. (1997). A rapid and reliable method for metabolite extraction in yeast using boiling buffered ethanol. Yeast 13, 1347-1356. 
Heinisch, J. (1986). Isolation and characterisation of the two structural genes coding for phosphofructokinase in yeast. $\mathrm{Mol}$ Gen Genet 202, 75-82.

Heinisch, J. J., Boles, E. \& Timpel, C. (1996). A yeast phosphofructokinase insensitive to the allosteric activator fructose-2,6bisphosphate. J Biol Chem 271, 15928-15933.

Hess, B., Boiteux, A. \& Kruger, J. (1969). Cooperation of glycolytic enzymes. Adv Enzyme Regul 7, 149-169.

Hoffman, C. S. \& Winston, F. (1987). A ten-minute DNA preparation from yeast efficiently releases autonomous plasmids for transformation of Escherichia coli. Gene 57, 267-272.

Hunsley, J. R. \& Suelter, C. H. (1969). Yeast pyruvate kinase: kinetic properties. J Biol Chem 244, 4819-4822.

Johnston, M. \& Carlson, M. (1992). Regulation of carbon and phosphate utilization. In The Molecular and Cellular Biology of the Yeast Saccharomyces, vol. 2: Gene Expression, pp. 193-281. Edited by E. W. Jones, J. R. Pringle \& J. R. Broach. Cold Spring Harbor, NY: Cold Spring Harbor Laboratory.

Kacser, H. \& Burns, J. A. (1973). The control of flux. Symp Soc Exper Biol 27, 65-104.

Kacser, H. \& Burns, J. A. (1979). Molecular democracy: who shares the controls? Biochem Soc Trans 7, 1149-1160.

Laemmli, U. K. (1970). Cleavage of structural proteins during the assembly of the head of bacteriophage T4. Nature 227, 680-685.

Meijer, M. M. C., Boostra, J., Verkleij, A. J. \& Verrips, C. T. (1998). Glucose repression in Saccharomyces cerevisiae is related to the glucose concentration rather than the glucose flux. J Biol Chem 273, 24102-24107.

Mellor, J. E., Dobson, M. J., Roberts, N. A., Kingsman, A. J. \& Kingsman, S. M. (1985). Factors affecting heterologous gene expression in Saccharomyces cerevisiae. Gene 33, 215-226.

Moore, P. A., Bettany, A. J. E. \& Brown, A. J. P. (1990a). The expression of a yeast glycolytic gene is subject to dosage compensation. Gene 89, 85-92.

Moore, P. A., Bettany, A. J. E. \& Brown, A. J. P. (1990b). Multiple copies of the pyruvate kinase gene inhibit yeast cell growth. J Gen Microbiol 136, 2359-2366.

Moore, P. A., Bettany, A. J. E. \& Brown, A. J. P. (1990c). The yeast pyruvate kinase gene is regulated at multiple levels. In PostTranscriptional Control of Gene Expression, pp. 421-432. Edited by J. E. G. McCarthy \& M. F. Tuite. Berlin: Springer.

Moore, P. A., Sagliocco, F. A., Wood, R. C. M. \& Brown, A. J. P. (1991). Yeast glycolytic mRNAs are differentially regulated. Mol Cell Biol 11, 5330-5337.

Ogden, J. E., Stanway, C., Kim, S., Mellor, J., Kingsman, A. J. \& Kingsman, S. M. (1986). Efficient expression of the Saccharomyces cerevisiae $P G K$ gene depends on an upstream activation sequence but does not require TATA sequences. Mol Cell Biol 6, 4335-4343.

Piper, P. W., Curran, B., Davies, M. W., Hirst, K., Lockheart, A., Ogden, J. E., Stanway, C., Kingsman, A. J. \& Kingsman, S. M. (1988). A heat shock element in the phosphoglycerate kinase gene promoter of yeast. Nucleic Acids Res 16, 1333-1348.
Planta, R., Brown, A. J. P., Cadahia, J. L. \& 13 other authors (1999). Yeast functional analysis reports: transcript analysis of 250 novel yeast genes from chromosome XIV. Yeast 15, 329-350.

Postma, E., Verduyn, C., Scheffers, W. A. \& van Dijken, J. P. (1989). Enzymic analysis of the Crabtree effect in glucose-limited chemostat cultures of Saccharomyces cerevisiae. Appl Environ Microbiol 55, 468-477.

Racker, E. (1947). Spectrophotometric measurement of hexokinase and phosphohexokinase activity. J Biol Chem 167, 843-854.

Reibstein, D., den Hollander, J. A., Pilkis, S. J. \& Shulman, R. G. (1986). Studies on the regulation of yeast phosphofructo-1-kinase: its role in aerobic and anaerobic glycolysis. Biochemistry 25, 219-227.

Schaaff, I., Heinisch, J. \& Zimmermann, F. K. (1989). Overproduction of glycolytic enzymes in yeast. Yeast 5, 285-290.

Sikorski, R. S. \& Hieter, P. (1989). A system of shuttle vectors and yeast host strains designed for efficient manipulation of DNA in Saccharomyces cerevisiae. Genetics 122, 19-27.

Strathern, J. N., Mastrangelo, M., Rinckel, L. A. \& Garfinkel, D. J. (1994). Ty insertional mutagenesis. In Molecular Genetics of Yeast: a Practical Approach, pp. 111-119. Edited by J. R. Johnston. Oxford: Oxford University Press.

Teusink, B., Baganz, F., Westerhoff, H. V. \& Oliver, S. G. (1998). Metabolic control analysis as a tool in the elucidation of the function of novel genes. In Yeast Gene Analysis: Methods in Microbiology, vol. 26, pp. 297-336. Edited by A. J. P. Brown \& M. F. Tuite. London: Academic Press.

Thomas, B. J. \& Rothstein, R. (1989). The genetic control of directrepeat recombination in Saccharomyces: the effect of rad52 and rad1 on mitotic recombination at GAL10, a transcriptional regulation gene. Genetics $123,725-738$.

Towbin, H., Staehelin, T. \& Gordon, J. (1979). Electrophoretic transfer of proteins from polyacrylamide gels to nitrocellulose sheets: procedure and some applications. Proc Natl Acad Sci US A 76, 4350-4354.

Van Schaftingen, E., Lederer, B., Bartrons, R. \& Hers, H.-G. (1982). A kinetic study of pyrophosphate: fructose-6-phosphate phosphotransferase from potato tubers. Eur J Biochem 129, 191-195.

Wicksteed, B. L., Collins, I., Dershowitz, A., Stateva, L. I., Green, R. P., Oliver, S. G., Brown, A. J. P. \& Newlon, C. S. (1994). A physical comparison of chromosome III in six strains of Saccharomyces cerevisiae. Yeast 10, 39-57.

Ye, L., Kruckelberg, A. L., Berden, J. A. \& van Dam, K. (1999). Growth and glucose repression are controlled by glucose transport in Saccharomyces cerevisiae cells containing only one glucose transporter. J Bacteriol 181, 4671-4675.

Yun, S. L., Aust, A. E. \& Suelter, C. H. (1976). A revised preparation of yeast (Saccharomyces cerevisiae) pyruvate kinase. J Biol Chem 251, 124-128.

Received 7 July 2000; revised 6 November 2000; accepted 7 November 2000. 